\title{
State-Space Modeling and Performance Analysis of Variable-Speed Wind Turbine Based on a Model Predictive Control Approach
}

\author{
Hussain Bassi \\ Electrical Engineering Department \\ Faculty of Engineering \\ King Abdulaziz University \\ Rabigh, Saudi Arabia \\ hmbassi@kau.edu.sa
}

\author{
Youssef Mobarak \\ Electrical Engineering Department, Faculty of Engineering \\ King Abdulaziz University, Rabigh, Saudi Arabia \& \\ Electrical Engineering Department, Faculty of Energy \\ Engineering, Aswan University, Egypt \\ ysoliman@kau.edu.sa
}

\begin{abstract}
Advancements in wind energy technologies have led wind turbines from fixed speed to variable speed operation. This paper introduces an innovative version of a variable-speed wind turbine based on a model predictive control (MPC) approach. The proposed approach provides maximum power point tracking (MPPT), whose main objective is to capture the maximum wind energy in spite of the variable nature of the wind's speed. The proposed MPC approach also reduces the constraints of the two main functional parts of the wind turbine: the full load and partial load segments. The pitch angle for full load and the rotating force for the partial load have been fixed concurrently in order to balance power generation as well as to reduce the operations of the pitch angle. A mathematical analysis of the proposed system using state-space approach is introduced. The simulation results using MATLAB/SIMULINK show that the performance of the wind turbine with the MPC approach is improved compared to the traditional PID controller in both low and high wind speeds.
\end{abstract}

Keywords-blades; maximum power point trackers; modeling; predictive control; turbines

\section{INTRODUCTION}

Wind energy has known wide research interest over the past years [1-4]. Research focuses on various aspects such as reliability [5], system stability, security, low-voltage ridethrough faults, energy profile, current movement, the short circuit flows and responsive power ability [6]. Variable-speed wind turbines play a key role in energy harvesting. They enhance energy production and reduce drive train rotations as well as fluctuations in power production [7-9]. Design and implementation of the regulation method for wind energy conversion systems (WECS) is a complex process. Complexity results from the multi-input multi-output (MIMO) systems which consist of robustly attached variables. The nonlinear nature of the input power and the natural hindrances of the system differences also cause difficulties to the regulation design [10-12]. There are several control techniques that have been used to maximize wind turbine efficiency. In the industry, most of the commercial wind turbines are operated by controlling the blade pitch angle. These controllers are divided into main categories; linear and nonlinear. For instance, linear controllers are able to regulate wind turbines using pitch angle control after the system has been linearized. They are also extensively used together with quadratic Gaussian or quadratic regulator to control the output power [13-14]. The design process undertaken for the proportional integral derivative (PID) and the proportional integral (PI) has also been examined together with the regulators [15-18]. Since wind systems have highly nonlinear characteristics, the performance of the system may be diluted with the operating point diverge from the linearized range.

Gain scheduling control is another linear technique that has been suggested as a way of introducing the linear features in the power systems. Although this technique outperforms PID and PD methods by widening the operation point range, it is limited in terms of the level of performance they offer to the wind turbines with non-linear characteristics [19-23]. Model predictive control (MPC) is one of the nonlinear control methods to improve the performance of the WECS that has attracted attention. There are two sub-categories derived within the electrical area of the MPC drives. The first category is based on the advancement of the conventional field-oriented control in which changes are made to the internal current loops [24-26]. It is done with a MPC regulator without removing the modulator. In the second sub-category, the modulator is removed and the MPC controls the inverter [27-30]. A different form of MPC is the Model Predictive Direct Torque Control (MPDTC). It enhances direct regulation of the torque as well as rotor flux in the machines [31-34]. The computational process of this technique may become tedious if the prediction horizon is extended massively. The MPC technique is a newer version which is responsible for controlling the machines stator currents [35-38].

In this paper, MPC approach is used to create a reasonable pitch angle regulator integrated in a variable speed wind turbine system. Mathematics concepts, MIMO and WECS are projected. The main objective of this study is to determine and 
standardize the apprentice MPC system set in contrast to the PID system.

\section{WECS MODEL}

WECS changes electric energy from kinetic energy through a process where air streams are converted into electric energy. The conversion process takes place when wind causes the blades to rotate which in turn spins the turbines. The spinning rotor drives the machine which then produces electricity. Currently, many wind turbines are built on the lateral design and consists of either two or three blades [2]. Energy transformation in the wind turbines takes place in four subsystems as illustrated below [4]:

- Electric generator model: this works together with the basics required for local grid connection. MPC or PID controls the inputs to generator model and pitch actuator system to improve wind turbine efficiency.

- Aerodynamic model: these are the blades for the turbine. Input factor consist of the speed of wind, how fast the rotor spins and the pitch angle. The output on the other hand consists of the rotation of the rotor which in turn produces electricity.

- Pitch actuator model: this part consists of a mechanical servo that rotates the turbine blades against the wind to regulate the generator rotor speed.

- Drive train model: involves the speed shafts, the turbine hub, and the speed multiplier. The input in this section constitutes the rotor rotation and speed multiplier which drives the train model. The rotor speed and shaft rotation make up the output.

Figure 1 shows the WECS model as a three-fundamental system that portrays a standard practice in WECS control. $\mathrm{T}_{\mathrm{r}}$ and $T_{g}$ are the rotor torque and generator torque input, and $\omega_{r}$ and $\omega_{\mathrm{g}}$ are the revolving speed of the rotor and the generator speed.

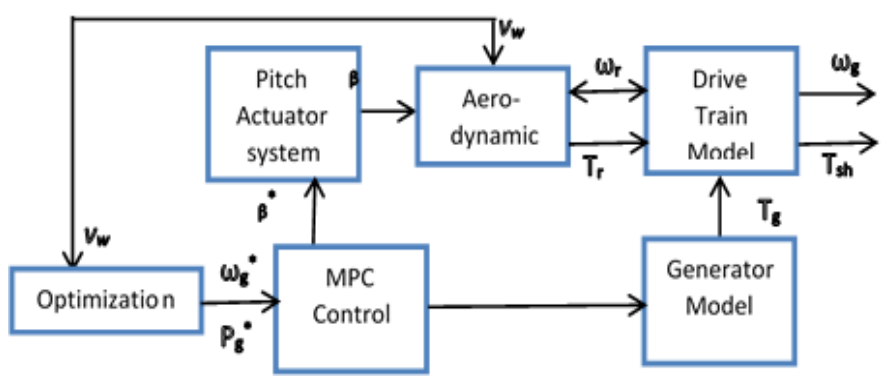

Fig. 1. Aerodynamic, mechanical and electrical models of the WECS.

Wind turbines have evolved form the traditional constant speed to the more efficient variable speed design. There are assumptions that wind turbines which generate levels of energy greater than the recorded speed are not cost effective. The energy curve is divided into three specific areas [10]. Area I constitutes mild wind speed lower that the rated power of the turbines, therefore the turbine is operated at the highest possible level. Area II is the transformation area and responsible for reducing the level of noise. Lastly, area III experiences high wind speed and it is where the turbine derives their highest level of power. At this level, the wind turbines are regulated within the limits of the optimal energy. The variablespeed variable-pitch WECS is made up of two operating areas [11]. First, the partial load regime consists of all the different wind speeds and rotors of the wind turbine responsible for achieving the highest level of performance. Secondly, the full load regime consists of wind turbines which are run when the speeds level are high or below the $\mathrm{v}_{\mathrm{co}}$. The control systems in this area controls the output energy and the speeds of generator based on their expected speed levels. It is known as the ratio of recorded output of energy to the free stream-like power flowing in the same area. The tip speed ratio $\lambda$ is defined as the speed of the wind turbine at the highest part of the blade to the free stream speed of wind. The speed on the tip of the blade has to reach a certain speed so that the wind turbine can generate maximum energy [10]. Utilizing an efficient control technique such as MPC will produce this desirable outcome. The highest output energy released does not flow in the same direction as the highest torque level. Both follow different laws with the output energy following the cube law while the torque takes the square law.

\section{A. Wind Turbine Aerodynamics System}

The aerodynamic system converts wind energy into useful mechanical energy. A thorough discussion about wind turbine aerodynamics can be found by reading [16]-[20]. It is important to understand the equations about the torque and how power is captured by the blades. Figure 2 illustrates three aspects (wind, energy curve, and responsiveness to wind fluctuations) of capturing wind energy. The energy and torque derived from the wind is shown in the equations below:

$$
\begin{aligned}
& \mathrm{P}_{\mathrm{w}}=\frac{1}{2} \mathrm{C}_{\mathrm{P}}(\lambda, \beta) \rho \pi \mathrm{R}^{2} \mathrm{v}_{\mathrm{w}}^{3} \\
& \mathrm{~T}_{\mathrm{a}}=\frac{1}{2} \mathrm{C}_{\mathrm{T}}(\lambda, \beta) \rho \pi \mathrm{R}^{3} \mathrm{v}_{\mathrm{w}}^{2}
\end{aligned}
$$

Where:

$\mathrm{P}_{\mathrm{w}}$ is the extracted power from the wind, $\mathrm{T}_{\mathrm{a}}$ is the aerodynamic torque of the rotor, $\rho$ is the air density, $\mathrm{R}$ is the radius of the blades, $v_{w}$ is the wind velocity, $C_{P}$ is the power coefficient, $\beta$ is the pitch angle of the rotor blades and $C_{T}$ is the aerodynamic coefficient.

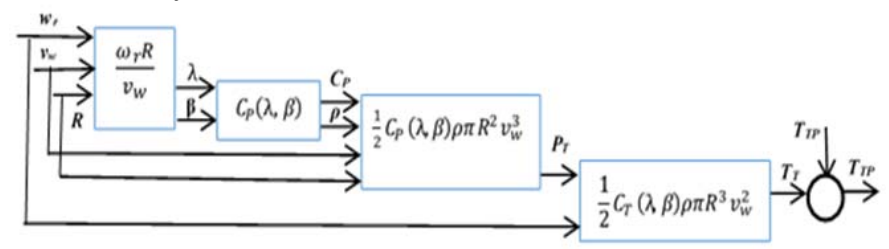

Fig. 2. Block diagram of the aerodynamic wind turbine model

$\mathrm{C}_{\mathrm{P}}$ and $\mathrm{C}_{\mathrm{T}}$ are nonlinear functions with respect to the tip speed ratio and the pitch angle and have the following relation, $\mathrm{C}_{\mathrm{P}}(\lambda, \beta)=\lambda \mathrm{C}_{\mathrm{T}}(\lambda, \beta)$. Where $\lambda$ is tip speed ratio which is the ratio between the blade tip speed and the wind speed upstream the rotor and is given as: 


$$
\lambda=\frac{\omega_{\mathrm{r}} \mathrm{R}}{\mathrm{v}_{\mathrm{w}}}
$$

where $\omega_{\mathrm{r}}$ is the rotational speed of the rotor in $(\mathrm{rad} / \mathrm{s})$ and $\mathrm{V}_{\mathrm{w}}$ is effective wind speed $(\mathrm{m} / \mathrm{s})$.

The blades are designed to ensure the highest energy coefficient outcome at the best speed on the tip speed ratio $\lambda_{\text {opt }}$. The energy coefficient is based on the speed at the tip and will fall under $0 \leq \mathrm{C}_{\mathrm{P}} \leq 0.4$. However, it will not be able to attain the maximum value $\mathrm{C}_{\mathrm{p} \text {-Betz }}$, referred to as Betz Limit, $\mathrm{Cp}<\mathrm{Cp}$ Betz $=0.593$ [18]. The equation below illustrates utmost collected energy and aerodynamic torque of the wind turbine:

$$
\begin{aligned}
& \mathrm{P}_{\max }=\frac{1}{2} \mathrm{C}_{\mathrm{P}, \max }\left(\lambda_{\text {opt }}, \beta\right) \rho \pi \mathrm{R}^{2} \mathrm{v}_{\mathrm{w}}^{3} \\
& \mathrm{~T}_{\mathrm{a}, \max }=\frac{1}{2 \lambda_{\text {opt }}^{3}} \mathrm{C}_{\mathrm{P}, \max }\left(\lambda_{\text {opt }}, \beta\right) \rho \pi \mathrm{R}^{5}
\end{aligned}
$$

\section{B. Pitch Actuator System}

This is a non-linear system that rotates the wind turbine blades. It is created using the saturation of the amplitude which can be modeled as mathematical dynamic equations [23]. Figure 3 demonstrates the first-order system of the actuator. The equation below illustrates the changing performance of the pitch actuator.

$$
\beta^{*}=\left(\frac{1}{\tau}\right) \beta_{d}-\left(\frac{1}{\tau}\right) \beta
$$

where: $\beta_{\min } \leq \beta \leq \beta_{\max }, \beta_{\min }{ }^{*} \leq \beta^{*} \leq \beta_{\max }{ }^{*}, \beta$ the actual pitch angle $\left(0-45^{\circ}\right)$ with $\pm 10 \%$ max and $\beta^{*}$ the desired pitch angle.

After calculating the desired pitch angle, the error in the closed loop has to go through a pitch angle limiter to bound the rate of change on the blades angle which results in increasing the blades lifetime [24].

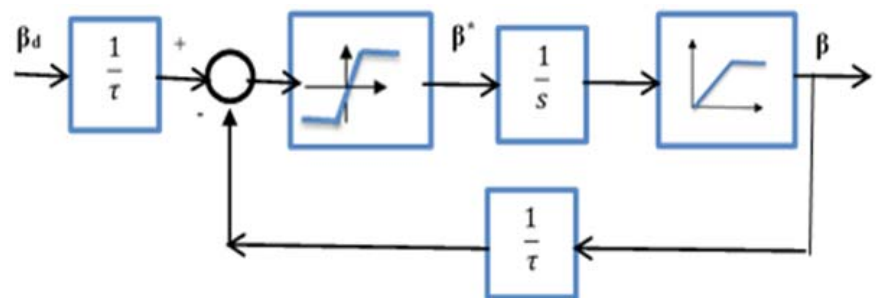

Fig. 3. Pitch angle actuator model

\section{Drive Train System}

Figure 4 shows the model made up of two mass mechanical models which are connected using a shaft with damping and stiffness coefficients. This shaft can be modeled as a torsion spring connecting two masses [26]. The mechanical model using the motion laws can be described as:

$$
\begin{gathered}
\omega_{\mathrm{T}}=\frac{1}{\mathrm{~J}_{\mathrm{T}}}\left(\mathrm{T}_{\mathrm{T}}-\left(\mathrm{K}_{\mathrm{s}} \delta \theta+\mathrm{B} \delta \omega\right)\right) \\
\dot{\theta}=\delta \omega
\end{gathered}
$$

$$
\begin{gathered}
\omega_{g}=\frac{1}{J_{G}}\left(\frac{1}{n_{\text {gear }}}\left(K_{s} \delta \theta+B \delta \omega\right)-T_{g}\right) \\
\delta \theta=\theta_{\mathrm{T}}-\theta_{\mathrm{g}} \\
\delta \omega=\omega_{\mathrm{T}}-\frac{\omega_{\mathrm{g}}}{\mathrm{n}_{\text {gear }}}
\end{gathered}
$$

\section{Generator System}

It is important to model only the generator side converter considering the control system design of the wind turbine. The following equation represents the overall component of the generator torque control action by the generator side for second-order dynamic system:

$$
\frac{\mathrm{T}_{\mathrm{g}}(\mathrm{s})}{\mathrm{T}_{\mathrm{g}}^{*}(\mathrm{~s})}=\frac{\omega_{\mathrm{ng}}^{2}}{\mathrm{~s}^{2}+2 \xi_{\mathrm{ng}} \omega_{\mathrm{ng}}^{2} \mathrm{~s}+\omega_{\mathrm{ng}}^{2}}
$$

Where $\mathrm{T}_{\mathrm{g}}{ }^{*}$ is the command value of the generator torque $\left(\mathrm{w}_{\mathrm{ng}} \approx 40 \mathrm{r} / \mathrm{s}\right)$ is the natural frequency, and $\left(\xi_{\mathrm{ng}} \approx 0.7\right)$ is the damping ratio.

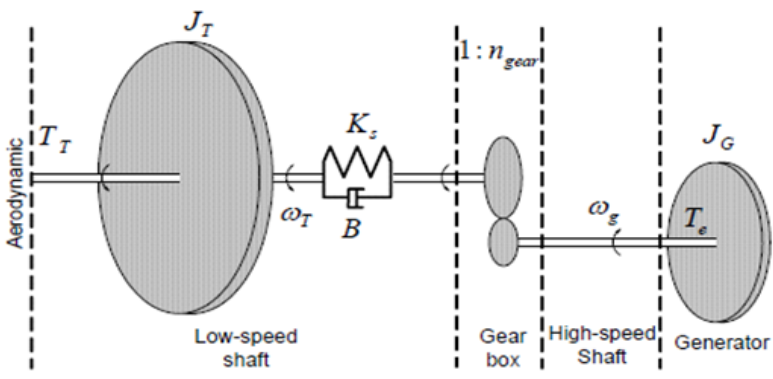

Fig. 4. Two mass model for the driven train

\section{LINEARIZED MODEL OF WECS}

According to the rotor, the aerodynamic rotation, non-linear function of wind speed, pitch angle and rotor speed can be formulated into linear equations as below:

$$
\delta \mathrm{T}_{\mathrm{a}}=-\beta_{\mathrm{w}}\left(\omega_{\mathrm{r}}, \mathrm{v}_{\mathrm{w}}, \beta\right) \delta \mathrm{w}_{\mathrm{r}}+-\beta_{\mathrm{v}}\left(\omega_{\mathrm{r}}, \mathrm{v}_{\mathrm{w}}, \beta\right) \delta \mathrm{v}_{\mathrm{w}}+-\beta_{\beta}\left(\omega_{\mathrm{r}}, \mathrm{v}_{\mathrm{w}}, \beta\right) \delta \beta
$$

Where:

For state space equation:

$$
\begin{aligned}
& \beta_{\mathrm{w}}\left(\omega_{\mathrm{r}}, \mathrm{v}_{\mathrm{w}}, \beta\right)=\left.\frac{\delta \mathrm{T}_{\mathrm{a}}}{\delta \mathrm{w}_{\mathrm{r}}}\right|_{\left(\omega_{\mathrm{r}}, \mathrm{v}_{\mathrm{w}}, \beta\right)} \\
& \beta_{\mathrm{v}}\left(\omega_{\mathrm{r}}, \mathrm{v}_{\mathrm{w}}, \beta\right)=\left.\frac{\delta \mathrm{T}_{\mathrm{a}}}{\delta \mathrm{v}_{\mathrm{w}}}\right|_{\left(\omega_{\mathrm{r}}, \mathrm{v}_{\mathrm{w}}, \beta\right)} \\
& \beta_{\beta}\left(\omega_{\mathrm{r}}, \mathrm{v}_{\mathrm{w}}, \beta\right)=\left.\frac{\delta \mathrm{T}_{\mathrm{a}}}{\delta \beta}\right|_{\left(\omega_{\mathrm{r}}, \mathrm{v}_{\mathrm{w}}, \beta\right)}
\end{aligned}
$$

$$
\begin{aligned}
& \dot{\mathrm{X}}=\mathrm{AX}+\mathrm{BU}+\mathrm{GW} \\
& \mathrm{Y}=\mathrm{CX}
\end{aligned}
$$

Where: 


$$
\begin{aligned}
& \mathrm{X}=\left[\begin{array}{lllll}
\delta \mathrm{w}_{\mathrm{r}} & \delta \mathrm{v}_{\mathrm{w}} & \delta \mathrm{T}_{\mathrm{sh}} & \delta \mathrm{T}_{\mathrm{g}} & \delta \beta
\end{array}\right]^{\mathrm{T}} \\
& \mathrm{U}=\left[\begin{array}{lll}
\delta \mathrm{T}_{\mathrm{g}}^{*} & \delta \beta^{*}
\end{array}\right]^{\mathrm{T}} \\
& \mathrm{Y}=\left[\begin{array}{lll}
\delta \mathrm{v}_{\mathrm{w}} & \delta \mathrm{P}_{\mathrm{g}}
\end{array}\right]^{\mathrm{T}}
\end{aligned}
$$

Then:

$$
\begin{aligned}
& \mathrm{A}=\left[\begin{array}{ccccc}
\frac{\beta_{w}}{J_{T}} & 0 & \frac{-N}{J_{T}} & 0 & \frac{\delta \beta_{\beta}}{J_{T}} \\
0 & 0 & 0 & 0 & 0 \\
K_{D} N+\frac{N D_{s h} \beta_{w}}{J_{T}} & -K_{s h} & -\left(\frac{N^{2} D_{s h}}{J_{T}}+\frac{D_{s h}}{J_{g}}\right) & 0 & \frac{N D_{s h} \beta_{\beta}}{J_{T}} \\
0 & 0 & 0 & \frac{-1}{\tau_{g}} & 0 \\
0 & 0 & 0 & 0 & \frac{-1}{\tau_{r}}
\end{array}\right] \\
& B=\left[\begin{array}{cc}
0 & 0 \\
0 & 0 \\
0 & 0 \\
\frac{1}{\tau_{g}} & 0 \\
0 & \frac{1}{\tau_{r}}
\end{array}\right], G=\left[\begin{array}{c}
\frac{\beta_{v}}{J_{T}} \\
0 \\
\frac{N D_{s h} \beta_{v}}{J_{T}} \\
0 \\
0
\end{array}\right] \text {, and } C=\left[\begin{array}{ccccc}
0 & 1 & 0 & 0 & 0 \\
0 & \tau_{r} & 0 & 1 & 0
\end{array}\right]
\end{aligned}
$$

Equation (13) shows the wind speed model based on (17) [28]. The model consists of tower shadow, rotational sampling and wind shear effects. The working positions are ascertained by the regulatory strategy. However, it has limitations such as energy, rotor, wind speed and pitch angle [32]. Equations (14) and (15), increase and assess the various wind speeds. Equations (14) and (15) are the linear model of the entire system. The state vector and the regulatory input are the assessed results. The system is described as MIMO which has a changing dynamics whenever there is a change of wind speeds.

\section{PROBLEM DESCRIPTION AND PROPOSED MPC APPROACH}

The main task is to regulate the rotor speed of the turbine which will in turn enhance the smoothness in the turbines making them efficient; especially at the limited load regime. The process however has a limitation which occurs during the creation of the regulator. The regulator is able to completely enhance the changed efficiency while at the same time reducing the temporary loads. The outcome indicated that variances existed between two objectives which required a balancing position [34]. The objective of regulation when operating at full load regime is to control the generator resulting energy and equally control the generator at set standards. The greatest limitation at this point is the big percentages of variations in the turbines energy. The percentages are caused by fluctuations in wind speed. The limitation also leads to a fluctuation in the drive train torsion torque as well as output electric power delivered to the grid. This power must be regulated thereby reducing the WECS apparatus and the flicker troubles [36].
Ordinary tests on the full load and partial regimes occur when the systems dynamics are not linear and viable variations occur at the operational center. Another test occurs when the system has cyclic aerodynamic torque difference and the turbine blades are rotating at three times their speed. This occurrence is known as the rotation sampling effect which is caused by uneven wind. Similarly, regulatory systems must identify regulatory goals kept at a certain level when facing limitations. For example, the highest level 1 is based on amplitude, speed pitch servos, generator energy and the speed of the turbines. Normally, variable speed and pitch consist of two working areas. The first is undertaken in partial load region with the aim of deriving the highest level of energy by regulating the turbine rotor speed. The second working area is the full load region where regulatory processes are able to alter the resulting energy as well as the speed of the generator at standardized figures. This creates difficulties especially in the WECS design since the MIMO system is not linear. In addition, factors such as the stochastic and sustainable differences of the speed of the wind and the restrictions by the system limit must be considered. The model illustrated above provides further complications to the regulatory design process. When assessed in the same level as the fixed speeds wind turbines, the variable speeds wind turbine has greater benefits such as increased production of energy on lower costs [37].

MPC control method can alter, regulate and predict perceptions of predictive models. It can also alter limitations and different weights. When varying scenarios are run on the system, which could either be linear or non-linear, the MPC can assess the regulatory performance. This can be seen in the altering of chemical processes and electromechanical systems. It is most beneficial when used in predictive model and is relevant in deriving regulatory actions by reducing certain functions which are objective. MPC optimization takes into consideration reduction of the variances existing in the predicted and reference parameters. The regulatory attempt is also based on the determined limitations. The MPC takes the following approach:

- The expected outputs for the anticipated prospect n, are predicted at each instant, $t$ using the process model.

- For $\mathrm{k}=1, \ldots, \mathrm{n}$, the predicted outputs $\mathrm{y}=(\mathrm{t}+\mathrm{k}(\mathrm{t}))$ depends on the known values up to instant $t$ (past inputs and outputs) and on the future control signals $\mathrm{u}=(\mathrm{t}+\mathrm{k}(\mathrm{t}))$, for $\mathrm{k}=0, \ldots, \mathrm{n}-1$, are calculated out of the process.

- The future control signals set is determined by an enhancing categorization to keep the process as close to the trajectory of the reference $\mathrm{w}=(\mathrm{t}+\mathrm{k})$.

- The reference trajectory can be the set point itself or a close approximation of it.

- Typically, this standard takes the appearance of a quadratic role of the errors between the predicted output signal and reference trajectory.

- The regulatory indication $\mathrm{u}(\mathrm{t})$ is taken to the system while the next regulatory indicator calculated the rejected, since the next sampling instant $y(t+1)$ is known and the step 1 is repeated with this new value. 
MPC model is vital in the prediction of future outputs arising from current values and expected future regulation action based on general composition as illustrated in Figure 5 . When using the linear model, over prediction are based on open and compulsory answers. The optimizer allows for the selection of the most beneficial regulation systems hence reducing cost functions. This is carried out by getting the weighted sum of the square predicted inaccuracy as well as square predictable regulatory figures. They are calculated at the high and low predicted possibilities and are known as the regulation perspective. The regulatory perspective allow the reduction allow the reduction in the predicted regulation based on the $\Delta \mathrm{u}(\mathrm{k}+\mathrm{j})$ for $\mathrm{J} \geq \mathrm{Nu}$. The $\mathrm{w}(\mathrm{k}+\mathrm{j})$. This signifies the location route over the regulatory perspective $N$.

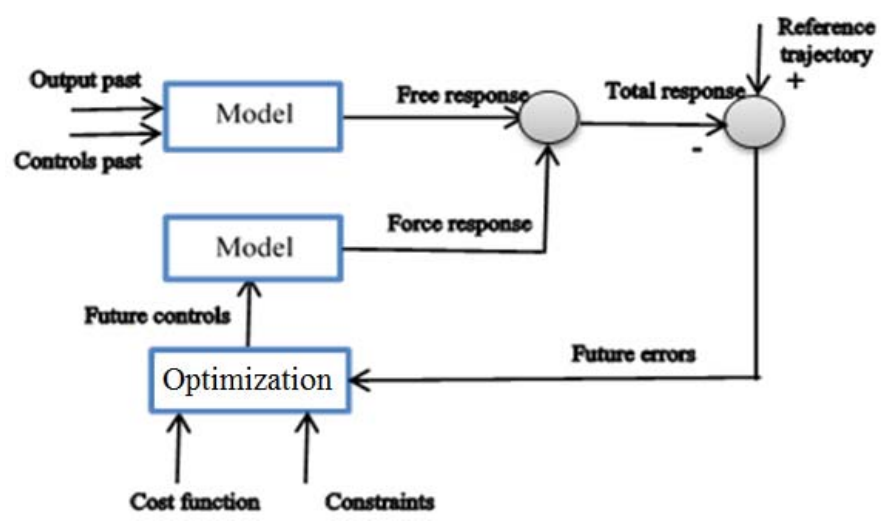

Fig. 5. MPC Controller

Limitations placed on the regulatory indicators, the outputs, and regulatory indicator varying can be included in the following equation:

$$
\mathrm{J}\left(\mathrm{N}_{1}, \mathrm{~N}_{2}, \mathrm{~N}_{\mathrm{u}}\right)=\sum_{j=N_{1}}^{N_{2}} \beta(\mathrm{j})(\mathrm{y}(\mathrm{k}+\mathrm{j})-\mathrm{w}(\mathrm{k}+\mathrm{j}))^{2}+\sum_{j=1}^{N_{u}} \lambda(\mathrm{j})(\mathrm{u}(\mathrm{k}+\mathrm{j})-1)^{2}
$$

If $\mathrm{N}_{1}, \mathrm{~N}_{2}$ fall at the bottom and highest prediction level on top of the results, then $\mathrm{Nu}$ is the regulatory possibility, $\beta(j), \lambda(j)$ are weighting variables. Limitation on the regulatory indicators, results as well as regulatory indicators varying can be included in equation below:

$$
\begin{aligned}
& u_{\text {min }} \leq u(k) \leq u_{\text {max }} \\
& \Delta u_{\text {min }} \leq \Delta u(k) \leq \Delta u_{\text {max }} \\
& y_{\text {min }} \leq y(k) \leq y_{\text {max }}
\end{aligned}
$$

The outcome of (16) derives the best order of regulation indicators based on the perspective $\mathrm{N}$ and at the same time recognizing limitation on (17). The MPC has many benefits such as the ability to control different systems, easy to use on complex systems, and offer prediction even if the outcome is delayed. Similarly, it can bring about the predicted results in systems which are closed loop. It can also be used to achieve the best outcomes with recognition of limitations. Although the benefits are diverse, it requires skills for anyone to model the system and handle its limitations. The MPC model is more complex as compared to PID since it requires more calculations.

\section{RESULTS AND DISCUSSIONS}

The considered $600 \mathrm{~kW}$ turbine system consists of three blades and pitch regulator. The feature of the MPC is an advantage over traditional PID controller including nonlinear control action. It can also reduce the noise, disturbance and parameters variations. The limitations for partial-load and fullload operations with MPC and with PID controllers are similar. They include wind velocity, angular momentum, pitch angle, generator power as well as torque output for 300 seconds. The system parameters are given in the appendix.

\section{A. Partial-Load Operation}

Figure 6 shows the results from the reputation exercise conducted for 300 seconds of partial-load WECS process. The outcomes reveal that the MPC and the PID regulators had identical tracing performance as observed in the speed and energy of the generator. This is resulted from the consistency of the return speed from the generator in tracking the maximum point tracking. Nevertheless, amounts of these speed and energy variations reduce with the use of the MPC control strategy. Therefore, the system has a better performance with MPC approach compared with traditional PID control.

\section{B. Full-Load Operation}

Figure 7 shows a duplicate outcome key for an operation that consists of a full load. It is important in examining the strength of the suggested MPC against uncertainties in the parametric. The power production when using the MPC leads to a more even and decreased fluctuation levels in the power output. The value of the decrease on the fluctuation of power production is enabled and enhanced based on the speed variations in the generator when compared to the PID control method as shown in Figure 7.Since the speed of wind, up to the first 50 seconds, is below the rated value of wind speed $(10 \mathrm{~m} / \mathrm{s})$ as shown in Figure 7a. In this period, the pitch angle is forced to level zero and the torque devolved is affected. From 50 to 218 seconds time period, the angle pitch is adjusted in order to extract the maximum power from the wind turbine above the rated wind speed as shown in Figure 7d.

Compared to the PID controller that forces the pitch angle to zero at early time of 218 seconds, the MPC approach enhances the wind power exploitation. Table I shows the evaluation of performance in the two systems and this arises because of the sustainable differences in the $\mathrm{wg}^{*}$ which follows the MPPT. However, the scales of these fluctuations reduce with the utilization of the MPC regulation approach. When the MPC is compared with other methods based on performance, the MPC is vital for either strong or mild wind speeds. Table I illustrates average speed in the generator, the average energy, as well as the highest pitch motion. The outcomes from Table I indicate captured power shut by union at the mild or strong wind speeds. Nevertheless, the highest level of the pitch angle was reduced by the MPC regulator as compared to the PID. The requested method proved most valuable as compared to other methods based on the level of performance. 

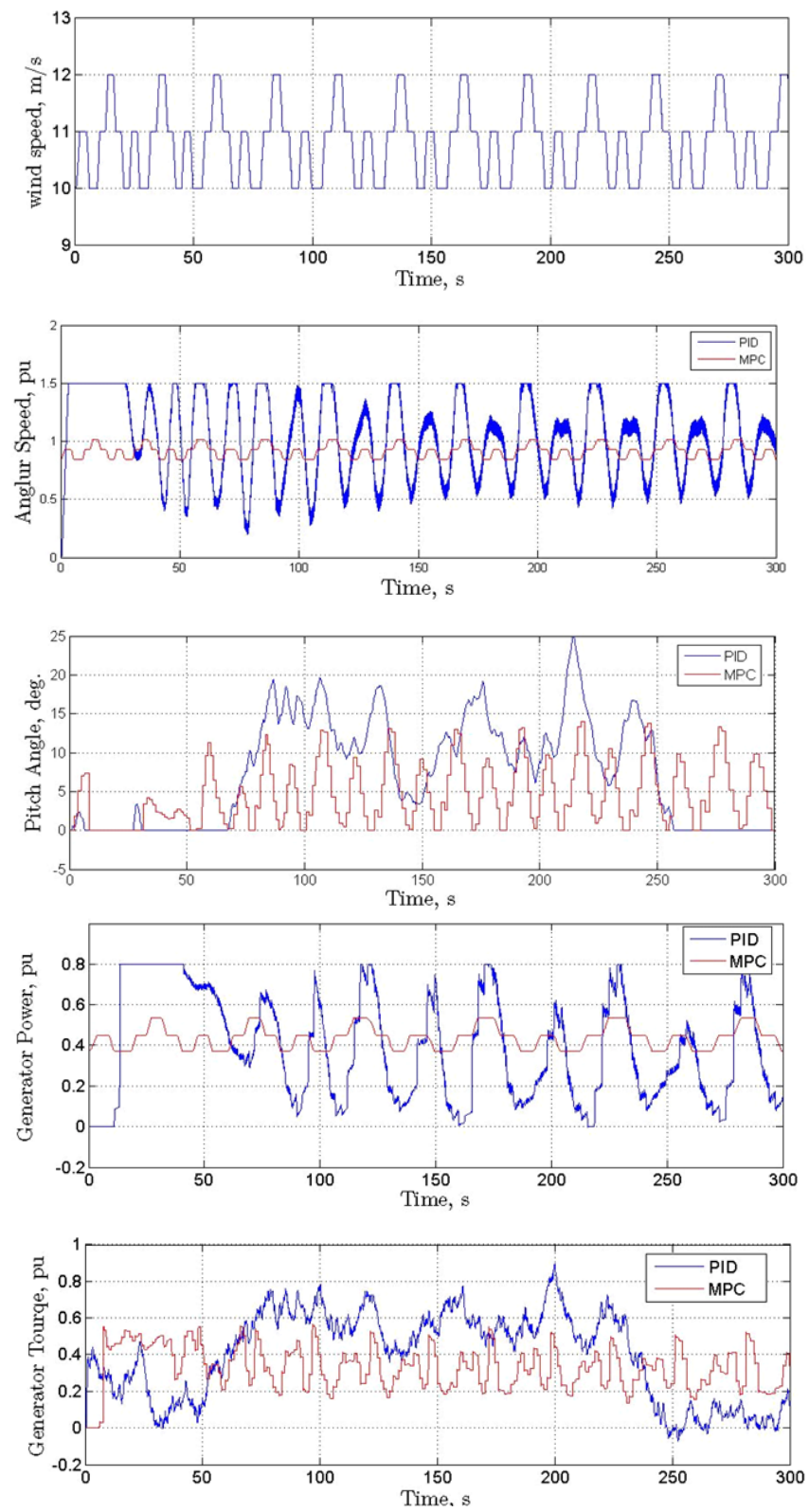

Fig. 6. Partial-load operation

TABLE I. OUTPUT PARAMETERS FOR MPC AND PID CONTROLLERS

\begin{tabular}{|c|c|c|c|c|}
\hline \multirow{2}{*}{ Item } & \multicolumn{2}{|c|}{ Mild wind velocity } & \multicolumn{2}{c|}{ Strong wind velocity } \\
\cline { 2 - 5 } & MPC & PID & MPC & PID \\
\hline Power output, pu. & 0.97 & 0.73 & 0.94 & 0.87 \\
\hline Pitch angle, deg. & 26 & 13 & 34 & 26 \\
\hline Generator speed, pu & 0.89 & 0.81 & 0.89 & 0.78 \\
\hline
\end{tabular}

\section{CONCLUSION}

The main objective of this paper is to examine the variable speed and the pitch turbine regulatory designs of WECS, with the goal of extracting maximum wind energy and enhancing the progress against full load and partial load operation. The paper illustrates how the MPC controller regulates the wind turbine and introduces a system which is dynamic based on its speed, pitch wind turbine as well as limitations in the of the rotation and pitch angle regulator. The system is modeled and simulated using MATLAB/SIMULINK. The obtained results at partial-load and full-load operations show that the studied system with the proposed MPC approach has a better performance compared to the traditional PID control in terms of speed response and energy extraction.
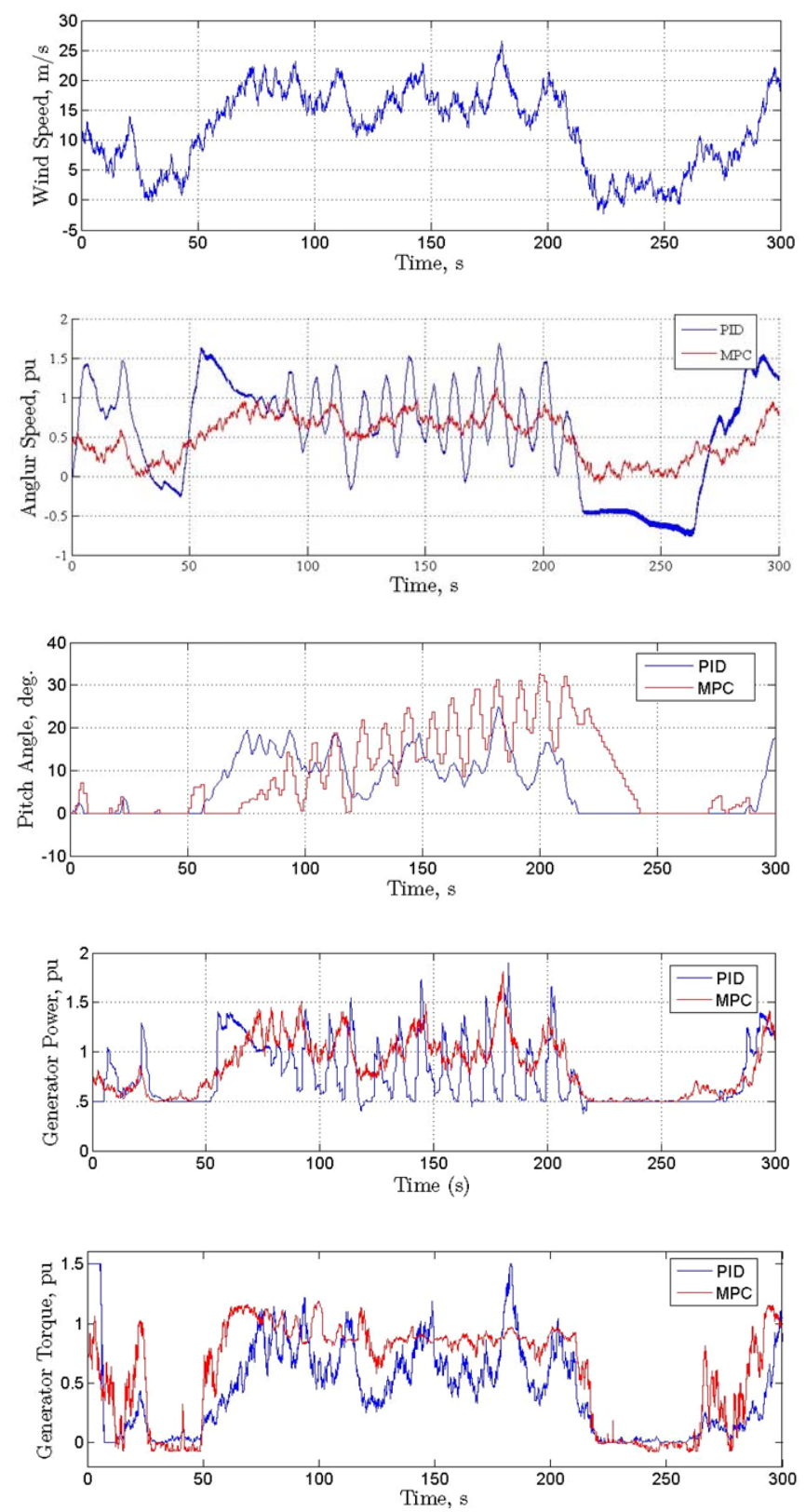

Fig. 7. Full-load operation

\section{ACKNOWLEDGMENT}

This project was funded by the Deanship of Scientific Research (DSR), King Abdulaziz University, Jeddah, under Grant no. (829-236D1435). The authors, therefore, acknowledge with thanks DSR's technical and financial support. 


\section{REFERENCES}

[1] P. Kundur, Power Systems Stability and Control, New York: McGrawHill, 1994

[2] L. Wang, Model Predictive Control System Design and Implementation using Matlab, Springer Australia, 2009

[3] P. C. Krause, O. Wasynczuk, S. D. Sudhoff, Analysis of Electric Machinery and Drive Systems, Hoboken, NJ: Wiley, 2002

[4] O. Anaya-Lara, N. Jenkins, J. B. Ekanayake, P. Cartwright, M. Hughes, Wind Energy Generation Modelling and Control, UK: John Wiley and Sons, 2009

[5] N. A. Ahmed, M. Miyatake, A. K. Al-Othman, "Hybrid Solar Photovoltaic/Wind Turbine Energy Generation System with VoltageBased Maximum Power Point Tracking", Electric Power Components and Systems, Vol. 37, No. 1, pp. 43-60, 2009

[6] G. Michalke, A. Hansen, T. Hartkopf, "Control Strategy of a Variable Speed Wind Turbine with Multi-Pole Permanent Magnet Synchronous Generator", European Wind Energy Conference EWEC, Milan, Italy, pp. 7-10, May 2007

[7] J. B. Ekanayake, L. Holdsworth, W. XueGuang, N. Jenkins, "Dynamic Modeling of Doubly Fed Induction Generator Wind Turbines", IEEE Transactions on Power Systems, Vol. 18, No. 2, pp. 803-809, 2003

[8] T. H. Mohamed, J. Morel, H. Bevrani, T. Hiyama, "Model predictive based load frequency control_design concerning wind turbines", International Journal of Electrical Power and Energy Systems, Vol. 43, No. 1, pp. 859-867, 2012

[9] C. E. Ugalde-Loo, J. B. Ekanayake, "State-Space Modelling of VariableSpeed Wind Turbines: A Systematic Approach", IEEE International Conference on Sustainable Energy Technologies (ICSET), Kandy, Sri Lanka, pp. 1-6, 2010

[10] C. E. Ugalde-Loo, J. B. Ekanayake, N. Jenkins, "State-Space Modeling of Wind Turbine Generators for Power System Studies", IEEE Transaction on Industry Applications, Vol. 49, No. 1, pp. $223-232$, 2013

[11] J. Morren and S. W. H. de Haan, "Short-Circuit Current of Wind Turbines With Doubly Fed Induction Generator," IEEE Transaction Energy Conversion, Vol. 22, No. 1, pp. 174-180, Mar. 2007

[12] M. Chinchilla, S. Arnaltes, J. C. Burgos, "Control of Permanent-Magnet Generators Applied to Variable-Speed Wind Energy Systems Connected to The Grid", IEEE Transactions on Energy Conversion, Vol. 21, No. 1, pp. $130-135,2006$

[13] F. Armansyah, N. Yorino, H. Sasaki, "Robust Synchronous Voltage Sources Designed Controller for Power System Oscillation Damping", Electrical Power and Energy Systems, Vol. 24, No. 1, pp. 41-49, 2002

[14] D. Q. Dang, Y.Wang, W. Cai, "Nonlinear Model Predictive Control (NMPC) of Fixed Pitch Variable Speed Wind Turbine," IEEE International Conference on Sustainable Energy Technology, Singapore, pp. 29-33, 2008

[15] F. Valenciaga, P. F. Puleston, "High-Order Sliding Control for a Wind Energy Conversion System Based on a Permanent Magnet Synchronous Generator", IEEE Transactions on Energy Conversion, Vol. 23, No. 3, pp. 860-867, 2008

[16] Y. Y. Hong, S. D. Lu, C. S. Chiou, "MPPT for PM Wind Generator using Gradient Approximation", Energy Conversion and Management, Vol. 50, No. 1, pp. 82-89, 2009

[17] H. Shayeghi, S. Jalilzadeh, H. A. Shayanfar, A. Safari, "Multi-machine Power System Stabilizers Design using Chaotic Optimization Algorithm", Energy Conversion and Management, Vol. 51, No. 7, pp. $1572-1580,2010$

[18] A. Jeevanandham, K.G. Thanushkodi, "Robust Design of Decentralized Power System Stabilizers using Meta-heuristic Optimization Techniques for Multimachine Systems", Serbian Journal of Electrical Engineering, Vol. 6, No. 1, pp. 89-103, 2009

[19] H. M. Hassan, A. L. Eishafei, W. A. Farag, M. S. Saad, "A Robust LMIbased Pitch Controller for Large Wind Turbines", Renewal Energy, Vol. 44, pp. 63-71, 2012
[20] Y. Joo, J. Back, "Power Regulation of Variable Speed Wind Turbines using Pitch Control Based on Disturbance Observer", Journal of Electrical Engineering Technology, No. 7, pp. 273-280, 2012

[21] M. Mirzaei, M. Soltani, N. K. Poulsen, H. H. Niemann, "An MPC Approach to Individual Pitch Control of Wind Turbines using Uncertain LIDAR Measurements", European Control Conference (ECC), Zürich, Switzerland, July 17-19, 2013

[22] M. Soltani, R. Wisniewski, P. Brath, S. Boyd, "Load Reduction of Wind Turbines using Receding Horizon Control", IEEE Conference on Control Applications, pp. 852-857, 2011

[23] T. Knudsen, B. Thomas, M. Soltani. "Prediction Models for Wind Speed at Turbine Locations in a Wind Farm", Wind Energy, Vol. 14, No. 7, pp. 877-894, 2011

[24] G. Shahgholian, "Development of State Space Model and Control of the STATCOM for Improvement of Damping in A Single-Machine Infinite Bus", International Review of Electric Engineering (IREE), Vol.4, No.6, pp.1367-1375, 2009

[25] W. Chao, Z. Yao, "Approach on Nonlinear Control Theory for Designing STATCOM Controller", IEEE International Conference on Grey Systems and Intelligent Services, pp. 871-875, 2007

[26] M. Mahdavian, G. Shahgholian, N. Rasti, "Modeling and Damping Controller Design for Static Synchronous Compensator", 6th International Conference on Electrical Engineering/Electronics, Computer, Telecommunications and Information Technology, pp. 300304, 2009

[27] Y. A. Mobarak, "FACTS Impacts Induction Generator Driven Wind Turbine", Journal of Engineering Sciences, Vol. 40, No. 4, pp.11571178,2012

[28] S. K. Sethy, J. K. Moharana, "Design, analysis and simulation of linear controller of a STATCOM for reactive power compensation on variation of DC link voltage", 2013 International Conference on Power, Energy and Control (ICPEC), 6-8 Feb. 2013

[29] M. Preindl, S. Bolognani, "Model Predictive Direct Speed Control with Finite Control Set of PMSM Drive Systems", IEEE Transactions on Power Electronics, Vol. 28, No. 2, pp. 1007-1015, 2013.

[30] T. Geyer, G. Papafotiou, M. Morari, "Model Predictive Direct Torque Control: Implementation and Experimental Evaluation", IEEE Transactions on Industrial Electronics, Vol. 56, No. 6, pp. 1906-1915, 2009.

[31] Y. Xie, R. Ghaemi, J. Sun, J. S. Freudenberg, "Model Predictive Control for a Full Bridge DC/DC Converter", IEEE Transactions on Control Systems Technology, Vol. 20, No. 1, pp. 164-172, 2012

[32] M. Darby, M. Nikolau, "MPC Current Practice and Challenges", Control Engineering Practice, No. 20, pp.328-342, 2012

[33] T. Geyer, "Model Predictive Direct Current Control: Formulation of the Stator Current Bounds and the Concept of the Switching Horizon", IEEE Transactions on Industrial Applied Management, Vol. 18, No. 2, pp. 4759,2012

[34] T. Geyer, "Computationally Efficient Model Predictive Direct Torque Control", IEEE Transactions on Power Electronics, Vol. 26, No. 10, pp. 2804-2816, 2011

[35] P. Cortes, J. Rodriguez, C. Silva, A. Flores, "Delay Compensation in Model Predictive Current Control of A Three-Phase Inverter," IEEE Transactions on Industrial Electronics, Vol. 59, No. 2, pp. 1323-1325, 2012

[36] T. Geyer, "A Comparison of Control and Modulation Schemes for Medium-Voltage Drives: Emerging Predictive Control Concepts Versus PWM-Based Schemes", IEEE Transaction Industrial Applied, Vol. 47, No. 3, pp. 1380-1389, 2011

[37] J. Scoltock, T. Geyer, U. K. Madawala, "A Comparison of Model Predictive Control Schemes for MV Induction Motor Drives", IEEE Transactions on Industrial Informatics, Vol. 9, No. 2, pp. 909-919, 2013

[38] M. Soliman, O. P. Malik, D. T. Westwick, "Multiple Model Predictive Control for Wind Turbines With Doubly Fed Induction Generators", IEEE Transactions on Sustainable Energy, Vol. 2, No. 3, pp. 215-225, 2011 